\title{
O saber-fazer do atendimento publicitário: as competências do profissional em atuação em São Borja, RS
}

\author{
Bruna Ferracine ${ }^{1}$ \\ Paloma Ferreira Sousa ${ }^{2}$ \\ Renata Patrícia Corrêa Coutinho ${ }^{3}$
}

\section{Resumo}

No intuito de descrever a forma de atuação e as competências do profissional de Atendimento publicitário no interior do Rio Grande do Sul, este artigo foi elaborado, a partir da reflexão teórica de vários autores, tais como: Gomes (2008), Corrêa (2006), Le Boterf (2003) e Dantas (2009). Como metodologia foi utilizada a pesquisa bibliográfica e a pesquisa de campo exploratória com a realização de entrevista em profundidade com os profissionais atuantes na cidade de São Borja a respeito de sua formação profissional, suas competências e o local em que trabalham. Como resultados, traçamos a forma de atuação e o perfil de profissional do atendimento de São Borja, que em sua maioria é formado pela Unipampa e atua conjuntamente no setor de planejamento.

Palavras-chave: Atendimento publicitário; São Borja; Agência de propaganda

\begin{abstract}
Abstact
In order to describe the form of performance and the competencies of the professional of Advertising service in the interior of Rio Grande do Sul, this article was elaborated, from the theoretical reflection of several authors, such as: Gomes (2008), Corrêa (2006), Le Boterf (2003) and Dantas (2009). As a methodology, bibliographic research and exploratory field research were used, with an in-depth interview with professionals working in the city of São Borja regarding their professional training, their skills and the place where they work. As a result, we have outlined the form of action and the profile of the São Borja service professional, who is mostly formed by Unipampa and works together in the planning sector.
\end{abstract}

Keywords: Advertising; São Borja.

\footnotetext{
${ }^{1}$ Bacharel em Comunicação Social com habilitação em Publicidade e Propaganda pela Universidade Federal do Pampa, Unipampa Campus São Borja, RS. ferracinebruna@gmail.com

2 Acadêmica de Publicidade e Propaganda da Universidade Federal do Pampa. palomauniversidade@gmail.com

${ }^{3}$ Doutora em Letras pela Universidade Federal de Santa Maria. Professora Adjunta da Universidade Federal do Pampa. renatacorreacoutinho@gmail.com
} 


\section{VOZES $_{\text {\&IÁLORO }}^{\mid}$}

Itajaí, V. 19, n.02, jul-dez 2020

\section{Introdução}

O presente artigo visa expor alguns dos resultados obtidos a partir das reflexões teóricas e da pesquisa de campo exploratória realizada com o objetivo de apresentar a forma de atuação e as competências do profissional de atendimento publicitário da cidade de São Borja, interior do Rio Grande do Sul.

Para situarmos o profissional de Atendimento publicitário, é preciso considerar que a publicidade acompanha tendências sociais, artísticas, assuntos do momento, desde seu surgimento e apresenta características que vão se alterando em função das práticas sociais, econômicas, políticas e tecnológicas de cada contexto. Variando de região para região com o intuito de fazer comprar, divulgar e até mesmo informar ou divulgar ideias, a publicidade adentrou os mais variados veículos de comunicação alcançando seus diversos públicos ao longo da história.

Diante disso, temos que o profissional de atendimento publicitário passou por várias fases em seu histórico. Na década de 1950, era visto como "dono da agência”, uma vez que o relacionamento pessoal do atendimento com o cliente era fundamental para manter a conta na agência de publicidade. Em alguns casos, quando o atendimento migrava de uma agência para outra, o cliente costumava ir junto, pois o atendimento, segundo Corrêa (2006) possuía grande "influência” sobre os demais departamentos.

Com o passar do tempo, o aumento no número de anunciantes foi tão grande, que as agências passaram a especializar seus profissionais para um mercado mais técnico. Sendo assim, o "dono da agência” deu lugar a um atendimento técnico (CORRÊA, 2006, p. 3637).

Em meados dos anos 70, após a apropriação da agência por tendências mais criativas e inovadoras, a criação passou a ter um maior destaque por meio da conquista de vários prêmios nacionais e internacionais. Por este fato, o destaque ao profissional de atendimento veio diminuindo cada vez mais, tornando-o um profissional como os demais, com seus valores e funções específicas, passando a ser considerado o responsável pela comunicação e negociação entre clientes e a agência e vice-versa (CORRÊA, 2006, p. 3738).

Atualmente, fica a cargo do profissional de atendimento a responsabilidade por manter contato direto e permanente com o cliente, dar assistência, estudar suas características, problemas e oportunidades, assim como planejar trabalhos e tarefas para solucionar problemas ou aproveitar oportunidades para a comunicação (SAMPAIO, 2003. p 60).

Profissional responsável pela relação da agência com o cliente e vice-versa, é ele quem conversa, media, faz reuniões, ouve, e descreve o problema de comunicação do cliente através do briefing, o qual se constitui em um resumo mercadológico que informa a agência todos os dados do cliente ou produto em questão para que estratégias de 


\section{VOZES $_{\text {\&IÁLORO }}^{\mid}$}

Itajaí, V. 19, n.02, jul-dez 2020

comunicação sejam criadas a fim de resolver o problema do anunciante (MARTINS, 2004, p. 32).

Para Corrêa (2006), o profissional de atendimento é a pessoa de negócios com base técnica em comunicação que possui a visão de conjunto que lhe permite uma melhor avaliação de alternativas de resolução de problemas. Ele consegue elencá-los e priorizá-los fazendo a inter-relação dos diversos fatos que prejudicam o cliente/anunciante na luta pela conquista do mercado. Tendo em vista a estrutura de uma agência, cada profissional tem suas habilidades e funções específicas e cada fase da criação de uma campanha é crucial para o desenvolvimento da publicidade. Desde o atendimento publicitário até a entrega final de resultados, a agência é responsável pelo cliente e a função de Atendimento, ainda que desempenhada por outros setores, carrega a responsabilidade de mediar e manter um bom relacionamento entre as partes envolvidas no processo.

\section{Competências do atendimento publicitário}

Por ser o atendimento publicitário o interesse principal desta pesquisa, aprofundaremos as competências profissionais desta área. Segundo Gomes (2008), o atendimento publicitário tem a função específica de manter relações técnico-profissionais com os anunciantes. Desta forma, o profissional de atendimento deve defender os interesses do cliente e da agência, atuando da melhor forma para que ambos estejam satisfeitos (GOMES, 2008. p. 150).

Sendo assim, quanto mais conhecimento se tem sobre o cliente, melhor será para descobrir ou solucionar problemas e criar estratégias de comunicação para determinado público. Partindo desse pressuposto, elencamos algumas características esperadas do profissional de atendimento, destacadas por Corrêa (2006) e Dantas (2009):

1) Criatividade: um profissional de atendimento criativo pode ser o diferencial competitivo da agência, afinal o conhecimento profundo que ele tem do cliente, abre portas para que alternativas criativas tragam resultados eficientes esperados, estabelecendo confiança e satisfação de ambas as partes (CORRÊA, 2006. p 61).

2) Formalismo: este também deve fazer parte do repertório do profissional de atendimento, pois o atendimento deve estar comprometido a fazer com que a agência atenda as expectativas do seu cliente. Deste modo, o profissional deve: registrar decisões em relatórios; acompanhar o trabalho dos outros setores (criação, mídia e produção); avaliar o trabalho antes de apresentá-lo ao cliente; apresentar a campanha para o cliente fundamentada em pesquisas; agilizar os procedimentos burocráticos necessários para aprovação da campanha; apresentar de forma clara ao cliente o que a criação quer transmitir expondo as peças da campanha bem como negociar o valor destas (DANTAS, 2009, p. 51-52). 


\section{VOZES $_{\text {\&IÁLORO }}^{\mid}$}

Itajaí, V. 19, n.02, jul-dez 2020

3) Discernimento: o profissional de atendimento deve ter discernimento para reconhecer as necessidades do cliente perante o mercado consumidor e dominar técnicas de prospecção de negócios e clientes. Também deve possuir um grande conhecimento sobre as técnicas de comunicação, como, quando e onde aplicá-las, pois os profissionais deste setor desenvolvem seu trabalho pautado no processo de liderança e na tomada de decisões com visão técnica e de mercado.

4) Entendimento das responsabilidades: o atendimento deve saber cumpri-las, tendo em mente que o planejamento é a base das contas publicitárias. Além disso, o profissional de atendimento tem de acompanhar as contas e supervisioná-las, sendo necessário saber administrar e controlar mídias para que seja estabelecido um relacionamento entre empresa, agência e veículos (DANTAS, 2009, p. 52-54).

Para além das características destacadas acerca do atendimento, o autor faz algumas recomendações que, segundo ele, o cliente enxerga com peso substancial, sendo elas: a aparência, com atenção ao tipo de vestimenta e comportamento apropriados a ocasião; hábitos de leitura que possibilitem ampliar o conhecimento e estabelecer um bom nível de conhecimento de vários assuntos, além dos conhecimentos específicos da comunicação; a pontualidade na entrega dos serviços e nas reuniões, fator que amplia a percepção da credibilidade e do profissionalismo; a capacidade para ouvir e prestar atenção no que está sendo dito. Ou seja, não há obviamente um manual de regras a ser seguido, mas é fundamental que o profissional esteja atento aos pequenos detalhes que otimizam uma boa relação entre as partes, gerando lucro tanto para a agência quanto para o cliente (DANTAS, 2009, p. 54-56).

Ferrari (1990) também aponta atribuições significativas no que se refere às funções do atendimento, tais como: analisar o problema comercial do cliente e transmiti-lo de forma traduzida para a agência através do briefing (FERRARI, 1990, p. 62); determinar objetivos para limitar até onde a publicidade irá ajudar o cliente; elaborar planos trabalhando juntamente ao setor de planejamento; orientar e acompanhar a execução das ações propostas; realizar avaliação das diversas etapas do trabalho, corrigindo o que for necessário e revisando o plano original quando preciso; fazer relatórios sobre pedidos e aprovações, documentando a conta; além de "estabelecer uma relação de confiança mútua e empatia entre agência e cliente (parceria)” (FERRARI, 1990, p. 62).

Em acréscimo a essas atribuições, Gomes (2008) destaca que o profissional de atendimento publicitário deve ter conhecimento sobre relações humanas, boa cultura, saber facilitar conversas e negociações, e dependendo do porte da agência ou do cliente, deve saber um idioma estrangeiro. Em suma, os autores mencionados destacam características desejáveis para a atuação profissional do atendimento publicitário às quais agregamos o que Le Boterf (2003) define como competências do profissional podendo estas ser entendidas como seus saberes teórico, do meio e procedimental, os quais constituem o saber fazer. 


\section{VOZES $_{\text {\&IÁLORO }}^{\mid}$}

Itajaí, V. 19, n.02, jul-dez 2020

\section{O saber-fazer}

Para Le Boterf (2003) o profissional não é aquele que possui habilidades ou conhecimentos, mas sim, aquele que sabe usá-los no cotidiano profissional; além disso, o autor destaca que um bom profissional além de dominar técnicas deve saber executá-las em diferentes contextos, como em situações de competitividade ou estresse, por exemplo.

Diante disso, temos que a competência se compara a um ato de enunciação onde o profissional é um ator que por meio de situações em que se encontra atua de forma a agir no contexto em que se encontra. Isto é, o profissional de atendimento, tem de ser um ator, que manifesta e se move sem que haja uma ação pré-determinada, ou seja, deve agir conforme os imprevistos e improvisar quando necessário.

Segundo Le Boterf (2003, p. 48), a competência é a combinação do saber mobilizar com o saber combinar recursos, diante disto o autor lista os recursos incorporados ao profissional a partir dos saberes teórico, do meio e procedimental.

O saber teórico é aquele que serve para entender um objeto, uma situação, fenômeno, um processo ou uma situação. Trata-se de um "saber que" ao invés de "saber como" (LE BOTERF, 2003, p. 95). O saber do meio ou ambiente se refere ao "lugar", ambiente em que o profissional intervém, ou seja, o profissional deve compreender os componentes que o rodeiam. O último saber trata-se do saber procedimental, este faz menção ao "como deve ser feito", ou seja, o "saber como" proceder para algo. Neste saber, as ações são vistas como algo a ser realizado, e para tanto, é preciso agir e saber como fazêlo.

A seguir, trazemos alguns dos resultados obtidos a partir dos conceitos apresentados anteriormente e da pesquisa de campo exploratória realizada com profissionais de atendimento publicitário da cidade de São Borja, interior do Rio Grande do Sul, com o objetivo de descrever a forma de atuação e as competências neles identificadas. Muito tem sido produzido sobre a atividade publicitária praticada nos grandes centros, como Porto Alegre, por exemplo. Entretanto, percebemos uma lacuna acerca dos processos de caracterização do setor e da atuação dos profissionais de atendimento realizados no interior do estado.

Até mesmo as associações de classe como Associação Brasileira de Agências de Publicidade, Associações dos Profissionais de Propaganda e Sindicados dos Profissionais de Publicidade do Estado do Rio Grande do Sul, pouco conhecem acerca do funcionamento da atividade no interior. Dessa forma, temos que a apresentação deste artigo, contribui para dar visibilidade ao trabalho publicitário praticado no interior, nomeadamente neste caso, na cidade de São Borja, considerando especificamente os profissionais de atendimento da região da fronteira oeste do estado. 


\section{Os profissionais de atendimento publicitário da fronteira oeste do Rio Grande do Sul}

A partir de pesquisa realizada em 2015, com enfoque na descrição da forma de atuação do profissional de atendimento na fronteira oeste, precisamente na cidade de São Borja, a seguir, contextualizamos a região em relação às agências de publicidade.

A região da fronteira oeste é composta por 13 cidades, que abriga cerca de $5 \%$ da população do Rio Grande do Sul (BERTÊ at al., 2012). A economia predominante na região é a pecuária extensiva voltada para a produção de carne, o leite em menor escala e o arroz. A histórica cidade de São Borja, também conhecida como "Terra dos Presidentes”, berço de Getúlio Vargas e João Goulart, foi fundada em 1682 e é a primeira cidade dos Sete Povos das Missões sendo a mais antiga do Rio Grande do Sul e uma das mais antigas do Brasil, atualmente possui cerca de 61.671 residentes (sendo 89,41\% população urbana $\left.{ }^{4}\right)$.

A cidade não possui grandes veículos de comunicação, como emissora de televisão, mas nela estão localizadas as rádios Fronteira FM e Cultura AM, além de rádios comunitárias como Butuí e Navegantes FM e os jornais Folha de São Borja e O Regional que circulam pela cidade. Através desses veículos, as agências de publicidade exercem papel importante no município utilizando-os para anunciar as empresas.

Para além desses veículos, é possível destacar a presença do setor comercial e varejista da cidade que se utiliza de outras formas de divulgação, incluindo nelas, a divulgação online pelo uso de sites e mídias sociais e a utilização de meios alternativos de propaganda como carros de som, distribuição de flyers, painéis impressos, etc.

Outro fator importante, se deve ao fato que a cidade de São Borja é contemplada com a Universidade Federal do Pampa - Unipampa, que oferece cursos de Comunicação Social sendo um deles o de Publicidade e Propaganda, o qual traz benefícios tanto para a cidade quanto para a região no que diz respeito a formação profissional, assim como gera contribuições ao desenvolvimento econômico da região, fomentando inclusive a atuação do comércio local.

Para a delimitação da pesquisa com os profissionais que seriam entrevistados, realizamos uma pesquisa exploratória junto ao cadastro do Conselho Executivo das Normas-Padrão (CENP), o qual resultou em um total de 20 agências cadastradas situadas em sete cidades ${ }^{5}$ (de um total de 13 cidades) que formam a fronteira oeste. Das quais foi

\footnotetext{
${ }^{4}$ De acordo os dados retirados do último censo (2010) do IBGE

${ }^{5}$ As cidades são: São Borja; Itaqui; Alegrete; Uruguaiana; Rosário do Sul e Santana do Livramento.
} 


\section{VOZES $_{\text {\&IÁLORO }}^{\mid}$}

Itajaí, V. 19, n.02, jul-dez 2020

possível estabelecer contato com apenas sete ${ }^{6}$, resultando ao final no retorno efetivo de somente duas agências (uma da cidade de Itaqui e outra de Uruguaiana) que nos remeteram as respostas solicitadas por e-mail: um questionário com perguntas relacionadas ao Atendimento e sua atuação.

Com os resultados obtidos a partir desse contato inicial, percebemos que as agências dessas cidades não eram exclusivamente agências de publicidade, mas sim, tratavase de agenciadores que trabalhavam com vendas para negócios de múltiplos segmentos, desse modo, as respostas não contemplariam os objetivos que o estudo buscava realizar: caracterizar o perfil do profissional de atendimento publicitário em atuação nessa região, em sua forma de atuação e seu saber fazer.

Deste modo, restringimos o campo de pesquisa a cidade de São Borja, considerando as agências que foram localizadas em atuação por meio de contato com setores comerciais da cidade e buscas realizadas na web. Assim, tivemos a identificação de quatro agências de publicidade e uma empresa de consultoria e assessoria empresarial que também oferece serviços publicitários e gestão da comunicação para os clientes ${ }^{7}$, as quais identificamos neste artigo pelas letras $A, B, C, D$ e $E$ a fim de preservar-lhes o anonimato. Antes de mais nada, vale ressaltar que a maioria das agências não possuem cadastro no CENP, com exceção de apenas uma delas .

A seguir, apresentamos o histórico das agências, para a contextualização do campo da pesquisa. Logo, temos que: a agência $A$ não disponibilizou seu histórico para a pesquisa. A agência $B$ iniciou suas atividades em 2014 através de um projeto criado por um ex-aluno da Unipampa, o qual atua como Atendimento publicitário. A agência $C$ surgiu quando os sócios desta, perceberam a oportunidade de mercado publicitário em São Borja. A abertura da agência $D$ se deu em 2007, porém desde 1998, o proprietário/atendimento, prestava serviços de designn, como a produção de cartão de visita, flyer e outros produtos gráficos de pouca tiragem. E por último a agência $\boldsymbol{E}$ começou em meados de 2013, iniciada por um ex-professor de edição, que se mudou para outra cidade e lá adquiriu experiência com design, ao retornar à cidade começou a atuar como freela'.

\footnotetext{
${ }^{6}$ Os dados obtidos das 17 agências estavam desatualizados: telefones e dados cadastrais não correspondiam aos nomes existentes no CENP.

${ }^{7}$ Esta será tratada nesta pesquisa como agência, pois a partir dos dados coletados durante a entrevista identificou-se que ela também atua a partir da mesma lógica de funcionamento de uma agência de propaganda, com acréscimo de outros serviços de consultoria em gestão.

${ }^{8}$ Depois da falta de atualização dos dados obtidos (na fase exploratória deste estudo) junto ao cadastro de agências disponibilizado pelo CENP, este trabalho passou a considerar como objeto de interesse as agências situadas em São Borja, independentemente destas não possuírem cadastro junto ao referido Conselho.

${ }^{9}$ Freelancer ou freela é o "profissional autônomo que se autoemprega em diferentes empresas ou, ainda, guia seus trabalhos por projetos, captando e atendendo seus clientes de forma independente".
} 


\section{VOZES \\ ¿DIÁl DRO}

Itajaí, V. 19, n.02, jul-dez 2020

Para alcançar os objetivos propostos, o instrumento de pesquisa foi concebido como um questionário caracterizado pela separação de informações pessoais (1) e dos três saberes (teórico (2), do meio (3) e procedimental (4)), os quais referem-se aos saberes aplicados a profissão e a experiência profissional de cada entrevistado. A aplicação do questionário se deu por meio de entrevista em profundidade e para compor este artigo, realizamos um recorte de algumas das perguntas realizadas, sendo elas:

1) Informações pessoais: identificação da cidade de origem e a cidade atual do profissional de atendimento entrevistado;

2) Saber teórico do profissional: se o entrevistado possui graduação em publicidade, em qual instituição se formou; se percebe a aplicabilidade do que aprendeu na faculdade com a prática profissional e se o setor de atendimento já era considerado uma opção de prática profissional.

3) Saber do meio: questões sobre quantos profissionais de atendimento possui a agência em que trabalha e como esse setor é caracterizado; quantas contas atende no momento e qual o número máximo de contas que já gerenciou; se já participou ou exerce outras funções nas demais áreas e se o entrevistado usa algum sistema/programa/software para o gerenciamento de contas.

4) Saber procedimental: se o entrevistado sente a necessidade de adequar a linguagem e vestimenta ao cliente; se se considera um Atendimento de contas ou Gerenciador de contas; com que frequência realiza reuniões com os seus clientes e quais relatórios costuma redigir na agência; se quando discorda do cliente, como expõe essa insatisfação e de que forma; como é o processo de criação de um conceito de campanha na agência; pedimos também que descrevesse sua rotina de trabalho.

A seguir, trazemos alguns desses resultados.

\section{Resultados do estudo: o profissional de atendimento em São Borja}

Após entrevista com cinco atendimentos das agências A, B, C, D e E $\mathrm{E}^{10}$, os resultados apontaram que, na seção (1) informações pessoais, três dos entrevistados nasceram em São Borja, os outros dois, em Porto Alegre e Itaqui e todos trabalham em São Borja.

Na seção (2), quanto ao saber teórico, temos que este saber faz referência aos conhecimentos adquiridos antes da prática publicitária na agência. Quatro dos cinco

\footnotetext{
${ }^{10}$ Agências serão assim identificadas com a finalidade de manter o sigilo sobre suas identidades.
} 


\section{VOZES $_{\text {\&IÁLORO }}^{\mid}$}

Itajaí, V. 19, n.02, jul-dez 2020

entrevistados são formados em Publicidade e Propaganda pela Unipampa, campus São Borja e um dos entrevistados, adquiriu experiência com um ex-sócio da agência. De forma que somente um dos entrevistados não cursou Publicidade e Propaganda, os demais profissionais relataram que percebem a aplicabilidade do que aprenderam na faculdade em sua própria prática profissional cotidiana.

Os quatro entrevistados que possuem formação em Publicidade e Propaganda, relataram que a área de atendimento era uma opção desde a faculdade, porém, não era prioridade, como no caso dos entrevistados $\mathrm{B}$ e $\mathrm{C}$ que afirmaram essa escolha a partir do planejamento, área que se identificaram primeiramente; segundo eles, por serem áreas "similares", passaram também a se interessar pelo atendimento. Desta forma, pode-se perceber o aprendizado na área de Publicidade e Propaganda adquiridos por ambos os entrevistados, pois, vale ressaltar que os entrevistados formados, pela Unipampa, admitiram aplicar na prática o que aprenderam na faculdade.

Já em relação ao (3) saber do meio, de acordo Le Bortef (2003) é aquele saber que faz referência ao meio em que o profissional de atendimento trabalha. Buscando identificar se as agências têm algum segmento de atuação, percebeu-se que somente a agência $\mathrm{C}$ distingue um foco comunicativo que é a promoção, porém, não deixa de fazer a publicidade geral das contas que atende como é o caso das demais agências que possuem os setores de uma agência tradicional. O setor de atendimento das agências é caracterizado por um único Atendimento com exceção da agência E, que possui um profissional substituto.

A quantidade de contas que cada agência atende atualmente varia, sendo que A e D atendem quatro contas cada uma, B e E, atendem um total de cinco e seis, respectivamente, e $\mathrm{C}$ um contingente de nove clientes atualmente, mas já chegou a atender 12 contas. Ao perguntar se o Atendimento entrevistado já havia participado ou participa de outras áreas da agência, a resposta que se teve foi que todos exerciam também a função de planejamento com exceção da agência E, que assume a função de redator, e o Atendimento $\mathrm{D}$, que assume a área de criação também.

As agências, em sua maioria, afirmam usar programas que auxiliam no atendimento e organização das contas e prazos de entrega, além de todas contarem com o recurso de computadores em seus ambientes de trabalho. $\mathrm{O}$ destaque maior neste quesito fica a cargo da agência $\mathrm{C}$, que utiliza o software denominado Agência Sys, usado para a gestão das contas, e para a agência $\mathrm{D}$, na qual o proprietário e também atendimento entrevistado neste projeto, desenvolveu um programa para auxiliar sua própria atividade. "Eu sou programador também. Esse sistema eu já utilizei pago, mas depois desenvolvi um. É bem interessante, não só pelo trabalho, mas também pelo financeiro” (Atendimento D). Aqui, faz-se interessante relembrar Le Boterf (2003, p. 48-49), quando afirma que a competência requer uma instrumentalização em saberes e capacidades, e no caso do atendimento $\mathrm{D}$, especificamente, o programa desenvolvido por ele próprio. 


\section{VOZES $_{\text {\&IÁLORO }}^{\mid}$}

Itajaí, V. 19, n.02, jul-dez 2020

No que se refere ao (4) saber procedimental, isto é, aquele que diz respeito a forma de visualizar a maneira como o profissional de atendimento trabalha na agência. As respostas obtidas com os entrevistados acerca desse assunto fazem menção até mesmo a questão de vestimenta e linguagem adaptadas ao perfil de cliente. Quatro dos entrevistados dizem se adequar aos clientes, pois "uns são mais formais", como afirma o entrevistado C. $\mathrm{O}$ respondente $\mathrm{E}$ é o único a mencionar que não sente necessidade de adequação de vestimenta e linguagem.

Todos os profissionais entrevistados assumiram ser gerenciadores de contas, pois como relata o entrevistado $\mathrm{C}$, além de atender aos clientes, este também gerencia a conta planejando o ano comunicacional das empresas. "[Sou] Gerenciador de contas, pois além de atender, eu também administro essas contas, pagamento, prazos, horários, publicações” (entrevistado A). Ao questionar com que frequência os profissionais de atendimento se reuniam com os clientes, A, C e E, relataram fazer reuniões semanais, B a cada 15 dias e D diz reunir-se duas vezes por ano com os clientes de outra cidade, e uma vez por mês com os clientes do município, além de prestar assistência por internet.

Outro aspecto que a pesquisa buscava conhecer sobre os profissionais é se eles ao discordarem do cliente em relação a algo, explicitavam essa discordância e de que forma o faziam. $\mathrm{O}$ entrevistado A respondeu que sempre expõe quando tem opinião contrária ao cliente. $\mathrm{B}$, diz que não se deve confrontar o cliente, mas mostrar o melhor caminho, através da articulação. O participante $\mathbf{E}$ diz que é sempre sincero e explica ao cliente por que não concorda com o que ele quer. D procura mostrar por que acredita que de tal maneira esteja errado, mas afirma também que o cliente sempre tem razão. C relata mostrar o melhor para o cliente através de embasamentos. Como trazido anteriormente, segundo Gomes (2008), o profissional de atendimento deve defender os interesses do cliente junto a agência, bem como os interesses da agência junto ao cliente atuando de forma que ambos estejam satisfeitos (GOMES, 2008, p. 150). "Coisas que eu risquei do vocabulário, por exemplo, é “acho” (...). Eu não acho nada (...). Então, aí, vou embasando pra ele entender (...)” (entrevistado C).

Outro interesse da entrevista era saber quais relatórios os profissionais redigiam na agência, pois Dantas (2009, p.51-52) afirma que registrar decisões em relatórios é um dever do Atendimento publicitário até mesmo por formalismo. O entrevistado A menciona fazer relatórios de atividades realizadas. $\mathrm{B}$, relatórios mensais e $\mathrm{C}$, semanais. $\mathrm{O}$ participante $\mathrm{D}$ admitiu que após perceber que o cliente não lia os relatórios, parou de produzi-los e E, faz relatórios das reuniões com os clientes e depois repassa-os ao Atendimento principal.

Ao serem questionados sobre o funcionamento do processo de criação de um conceito na agência, pois, o objetivo era buscar saber se o profissional de atendimento também participava desse processo, obtivemos a resposta de que todos os entrevistados participavam do processo de criação. Por fim, os entrevistados deveriam descrever sua rotina diária na agência de Publicidade. Desse modo, o entrevistado A relatou atender aos 


\section{VOZES $_{\text {\&IÁLORO }}^{\mid}$}

Itajaí, V. 19, n.02, jul-dez 2020

clientes no período da tarde e não ter horário fixo para sair da agência. B, disse checar as atividades previstas para o dia no sistema, tentando vencê-las até o final do dia. O participante $\mathrm{C}$ afirmou revisar o que tem de ser feito para a semana bem como os materiais que precisarão de aprovação. $\mathrm{D}$, disse visualizar os e-mails, checar o gerente de serviços elencando as prioridades do dia, realizando visita a clientes e orçamentos para que estes sejam aprovados no dia. $\mathrm{O}$ entrevistado $\mathrm{E}$ afirma visitar as empresas, fazer reuniões na agência ou até mesmo receber visitas informais dos clientes.

Pudemos perceber, através dos dados aqui expostos, a existência de algumas características do atendimento publicitário destacadas pelos autores que mencionamos anteriormente, além disso, pudemos perceber que todos os profissionais de atendimento têm uma forma de trabalhar em comum. Assim como, Le Boterf (2003, p. 48) explica, o profissional é aquele que sabe aplicar no seu cotidiano as habilidades e os conhecimentos que possui. Ter saberes e técnicas não representa necessariamente a competência do profissional, pois este deve saber utilizá-los em sua prática profissional, ou seja, saber não é o mesmo que saber-fazer.

\section{Considerações finais}

Constatamos a partir dos resultados obtidos após a entrevista realizada com os profissionais de atendimento que as características mencionadas pelos autores estudados estão em consonância com a prática identificada no contexto estudado.

Podemos dizer que o Atendimento publicitário atuante em São Borja é formado pela Unipampa, e atua conjuntamente no setor de planejamento. A maioria dos profissionais entrevistados e formados pela instituição dizem perceber a aplicabilidade do que aprenderam na faculdade em sua prática cotidiana profissional, o que reafirma o imbricamento da teoria e da prática em consonância ao que Le Boterf (2003) traz em relação ao "saber teórico". Cabe ainda destacar que esse resultado aponta para a contribuição da instituição para a profissionalização da publicidade nesta região.

Podemos perceber a aplicabilidade do "saber do meio" trazido por Le Boterf (2003) quando os profissionais mencionaram utilizar recursos para gerenciarem as contas que atendem através de programas de gerenciamento. Em relação às agências nas quais os profissionais trabalham, todas tem um número de funcionários reduzido, o que parece ser condizente com o volume de contas atendidas. Convém ressaltar que diferentemente das regiões metropolitanas que possuem numerosas agências e profissionais em atuação correspondente às atividades comerciais pujantes dos grandes centros, a cidade de São Borja demonstra ainda não possuir um mercado publicitário consolidado.

A atuação do Atendimento publicitário também é caracterizada pelo "saber procedimental” trazido por Le Boterf (2003). Neste aspecto, a maioria dos profissionais se coloca atenta ao que o cliente fala, responsável por revisar a apresentação e a coerência 


\section{VOZES $_{\& \text { DIÁLORO }}^{\mid}$}

Itajaí, V. 19, n.02, jul-dez 2020

com o desejo do cliente explicitado no briefing. Além disso, o profissional de atendimento publicitário de São Borja exerce sua função de acordo com o que os autores citados anteriormente definem como competências, como, por exemplo, a relação e o comportamento perante o cliente para conquista de credibilidade.

Os entrevistados destacam a necessidade de se relacionarem com o cliente de forma a guiá-lo pelo melhor caminho, mesmo que eventualmente isso acarrete a discordância de ideias, uma vez que o atendimento é responsável por identificar as necessidades do cliente, para que a agência utilize seu conhecimento para construir a publicidade mais adequada a cada caso. Ainda no que se refere ao "saber procedimental", a pesquisa possibilitou identificar que o profissional de atendimento se mostra comprometido com a entrega nos prazos acordados, buscando manter contato com o cliente regularmente.

De modo geral, os resultados aqui apresentados correspondem ao objetivo delimitado para este artigo, isto é, apresentar a forma de atuação e as competências do profissional de atendimento publicitário da cidade de São Borja, correspondendo a necessidade de dar visibilidade aos processos de trabalho na publicidade praticados no interior do estado do Rio Grande do Sul, onde existe uma lacuna acerca dessa temática.

\section{Referências bibliográficas}

CORRÊA, Roberto. O atendimento na agência de comunicação. 1, ed. São Paulo: Global editora, 2006.

DANTAS, Edmundo Brandão. Gerenciamento de contas: uma abordagem aplicada a agências de comunicação publicitária. São Paulo: Atlas, 2009.

FERRARI, Flávio L. S. Planejamento e atendimento: a arte do guerreiro. São Paulo: edições Loyola, 1990.

GOMES, Neusa Demartini. Publicidade: comunicação persuasiva. Porto Alegre: Sulina, 2008.

IBGE. "Instituto Brasileiro de Geografia e Estatística" http://www.ibge.gov.br/home/ Acesso em 15 de novembro de 2015.

LE BOTERF, Guy. Desenvolvendo a competência dos profissionais. Porto Alegre: Artme, 2003.

MARTINS, Zeca. Propaganda é isso aí!: um guia para novos anunciantes e futuros publicitários. São Paulo: Atlas, 2004.

SAMPAIO, Rafael. Propaganda de A a Z. 3, ed. Rio de Janeiro: Elsevier, 2003.

“São Borja.” TGL Simpsons. Disponível em: https://tglsimpsons.wordpress.com/2012/04/01/pagina-historia-de-sao-borja/_Acesso em 15 de novembro de 2015. 